needs to be undertaken could be done on an international collaborative basis, perhaps co-ordinated through the Intergovernmental Maritime Consultative Organization.

Research is considered to be necessary into means of speedy transfer of the cargo from a stranded vessel and methods of firing oil in a stranded tanker and on the sea surface. The committee also recognizes the need to develop more effective but less toxic detergents and to investigate the effects of natural factors in the movement, dispersal and destruction of oil at sea, as well as of the factors determining the stability and formation of different types of oil-water emulsion. Other enquiries, it maintains, should be directed to the disposal of oil by sinking with high density material. The possibility of developing cheap, effective and floating oil-absorbent material and methods of collecting the oil-soaked material in open seas also needs to be examined. Gelling agents are at present expensive and cheaper ones need therefore to be developed. Furthermore, suitable coastal tankers equipped to spray detergent and to ensure that it is mixed with the oil are also desirable. Cheap and effective booms, primarily for protecting harbours and inlets, are not yet available but could prove useful if improved, while mechanical methods for removing oil from beaches and rocks could be reinforced by burning and steam cleaning-the latter having been used successfully in France. Finally, the committee maintains that further research is needed into the effect of oil and detergent on fish and other marine life, sea birds and coastal vegetation.

\section{Too Much Steel}

STEEL production capacity is considerably greater than the demand for it in OECD countries. This observation is made in the recently published OECD review of the iron and steel industries in member countries (The Iron and Steel Industry in 1966 and Trends in 1967 ; OECD, 21s.).

Overcapacity in the steel industry has been a source of increasing concern since 1958 and in Europe in 1966 production of steel was 20 million tons below capacity. This imbalance between supply and demand has had destructive consequences. To maintain large production runs manufacturers have been forced to set export prices at low levels, which has in turn affected domestic prices in many countries. The downward pressure on prices has diminished profits and the ability to maintain a level of essential investment has been seriously impaired.

WORLD PRODUCTION OF STEEL, MULLION TONS

\begin{tabular}{lrrr} 
& 1965 & 1966 & $\begin{array}{c}\text { Per cent } \\
\text { change }\end{array}$ \\
ECSC & $86 \cdot 0$ & $85 \cdot 1$ & $-1 \cdot 0$ \\
UK & $27 \cdot 4$ & $24 \cdot 7$ & $-10 \cdot 0$ \\
OECD_Europe & $127 \cdot 2$ & $124 \cdot 3$ & $-2 \cdot 3$ \\
Canada & $9 \cdot 1$ & $9 \cdot 1$ & $0 \cdot 0$ \\
United States & $119 \cdot 3$ & $121 \cdot 7$ & $+2 \cdot 0$ \\
Japan & $41 \cdot 2$ & $47 \cdot 8$ & $+16 \cdot 1$ \\
\hline OECD total & $296 \cdot 8$ & $302 \cdot 9$ & $+2 \cdot 0$ \\
\hline USSR & $91 \cdot 0$ & $96 \cdot 9$ & $+6 \cdot 5$ \\
Other countries (excluding China) & $56 \cdot 1$ & $60 \cdot 1$ & $+7 \cdot 1$ \\
\hline World (excluding China) & $443 \cdot 9$ & 459.9 & $+\mathbf{3} \cdot 6$
\end{tabular}

World production of steel continued to increase in 1966 but in Europe showed a small decline. Japan is the only large producer whose iron and steel industry experienced a significant increase in production. In the first half of 1967 output in the OECD area continued at about the same rate as that recorded for 1966; the upward trend continued in Japan, but the decrease in the United Kingdom and Germany showed signs of levelling out.

Two basic trends discernible in the international trade in steel are, first, a levelling off or even a decrease in exports to developing countries, and, second, an increase in trade between industrialized countries. Developing countries not only lack the foreign exchange to import steel but in many cases are supporting indigenous industries. The increasing volume of trade between industrialized countries is caused partly by the need to make good shortfalls in production in the countries concerned, and partly by geographical factors, price differences and such competitive conditions as quality, delivery and after-sales service.

Investment expenditure in 1966 again reached high levels in Canada, the United States and Japan, but in Europe was lower than previous years. (In the United Kingdom, at least, the impending nationalization of the industry was probably one of the factors inhibiting investment.) Investment in Europe was usually devoted to modernization and short-term improvements in productivity. The report concludes on the melancholy note that the chronic overcapacity in the steel industry seems likely to continue for many years to come. International efforts to avoid or even alleviate the effects of overcapacity have been unsuccessful. Instead, individual countries have increasingly preferred to take steps to safeguard their own iron and steel industries.

\section{Aluminium from Coal}

The British Government's plan to sell electricity cheaply to aluminium smelters in the hope of starting a new industry in Britain seems not to be going exactly as Mr Wilson intended. Alcan, an aluminium company based in Canada, has decided that it would prefer to buy its coal cheaply and build its own power station. The Government's intention was that the smelters should share the output of a large nuclear power station with the electricity boards, after paying a capital sum equivalent to the amount of electricity the smelter would need. Alcan has lent credence to the National Coal Board's claim that it is still possible to generate electricity more cheaply with coal than with nuclear power, and has at the same time given the electricity boards the uneasy feeling that Alcan is getting better terms than they are. Neither the coal board nor Alcan is revealing the price agreed for the coal, but it will be supplied in substantial amounts1 million tons a year when the smelter is operating fully.

The Coal Board has also had discussions with another aluminium company, Alusuisse, which announced some weeks ago that it was interested in tendering for a smelter. So far these seem only to have been tentative, and no decision has been reached. But, from the point of view of the aluminium companies, there is much to be said for building a small power station sufficient only for their own needs. This spares them the need to satisfy the stringent demands of the generating 
boards, and makes the process of running the station very much easier. Moreover, for a small station, coal is likely to be compctitive, while in the larger sizes the arguments in favour of cxpensive nuclear power stations are compelling.

The argument has bcen further complicated, perhaps deliberately, by the suggestion that Alcan might be willing to pay back to the British Government money it borrowed during the war to build aluminium plants in Canada. The sum involved is $\mathfrak{£ 5 0}$ million, and half was to be repayed in 1971, the other half in 1974. Repayment of this debt in dollars would be welcome for the beleaguered British economy. The Alcan plan would also be welcomed by the mining industry, which is eager to find new outlets for its products. The Coal Board says that most of the coal for the Invergordon smelter would come from the north-east coal field, and possibly some might come from Scotland.

So far the other aluminium companics which put in tenders for smelters-Rio Tinto Zinc and British Aluminium-are standing by their original intention to use nuclear stations. Meanwhile Alcan has other fish to fry-it is also to build a smelter in Japan, on the island of Hokkaido. The smelter, which will have a capacity of 130,000 tons (more than twice the size of the smelter proposed for Invergordon), is expected to come into full production in 1972. Production will start in 1970, and Alcan says that the Japanese market is expanding more quickly than any other. Although the 20 per cent annual expansion experienced between 1958 and 1967 is unlikely to be maintained, a more modest rate of expansion-perhaps 10 per cent a year - should still make Japan the second largest consumer of aluminium by 1972, after the United States.

\section{Causes of Death}

THE Area Mortality volume of the Registrar General's Decennial Supplement gives an analysis of deaths in England and Wales for the five years 1959-63. With the total number of deaths in the period being just over 2.7 million, the annual death rate per thousand of the population was just over 12.5 for males and just under $11 \cdot 3$ for females. Figures known as the Standardized Mortality Ratios (SMR), which are given to aid comparisons, express the actual number of deaths as a percentage of the "expected" number. Thus for the country as a whole the SMR is 100 .

Deaths from all causes and from the sixteen most widespread diseases are first analysed into ten regions and conurbations, and then into the nature of the area, whether rural or urban of varying sizes. Then follow analyses for hospital regions, London and county boroughs and finally administrative counties, which are split into urban and rural areas. Seventeen diseases which cause fewer deaths are then listed and the figures analysed into three categories only for region, nature of area and hospital region. Separate tables are given for males and females and, as well as totals for each cause of death, the figures are split into six age groups -under 1 year, $1-4,5-14,15-44,45-64$ and 65 and over. A separate table gives infant death rates from seven different causes, as well as the number of stillbirths and the live birth rates for the various areas. For the five year period the total number of live births was just over 4 million, indicating an excess of births over deaths of about 1.3 million for the five years.
'This supplement continues the series that has been produced by the Registrar General since 1851. It also continues to show that mortality was highest in the north-western region, as was found in the 1951 supplement. In general, rural districts had the lowest death rates, but density of population did not always produce high mortality. The SMRs for Greater London were below the national average for all causes, although those for lung cancer in the area were very high.

The large number of geological, economic and social factors involved in mortality figures complicate their interpretation. Official comment on the Area Mortality supplement is therefore to be published separately.

\section{Patients in Hospital}

THERE was an increase in the number of patients discharged from British hospitals in 1964, and a decrease in the average length of stay in hospital compared with 1962 and 1963. Men and boys stayed in hospital an average length of 18.3 days in 1964; women and girls (including maternity patients) averaged just under two days less (16.7 days). Between 1962 and 1964 there was also a drop in the number of beds occupied per million population. These are somc of the findings in Part 1 of the Report on Hospital In-Patient Enquiry for the year 1964, which has just been published on behalf of the Ministry of Health and the General Register Office (HMSO, 3ls.).

The report contains detailed tables prepared from the 1964 ten per cent sample of discharges and deaths recorded by National Health Service hospitals in Fngland and Wales, except those for psychiatric, pre-convalescent and convalescent patients. The hospital in-patient enquiry has two purposes which are closely related - to provide administrative data for the hospital services in terms of diseases treated and of the characteristics of the patients who had these diseases, and to provide information which can be of help in assessing the amount, distribution and effect of illness in the community and in various sections of it. Hospitals collect all the information by completing forms for one patient in every ten on discharge or death.

The tables are a mine of information. They include analyses by sex, age, region of residence and diagnosis, and by source of admission (that is, whether from a waiting list, immediate or other type of admission) and diagnosis. Many of the tables are connected with length of stay in hospital, and from this the average number of beds used daily and in relation to the total population has been calculated. These figures are shown for diagnostic group, age, sex, marital status, region of residence and hospital department (speciality) and certain combinations of these factors. Significant conclusions could no doubt be drawn from these figures and those for 1962 and 1963 . A discussion of the tables is in fact to be published later in a separate commentary volume covering the ycars 1962 to 1964 .

An innovation in the tables is the singling out of the place where accidents happened to people admitted to hospital. Injuries, poisonings and the like are all analysed in great detail according to whether they were caused by road traffic accidents, accidents in the home, or "other" mishaps. Not surprisingly, head injuries (excluding skull fractures) account for the 